\title{
Seeking the holy grail of markers
}

\author{
Marco Anile, Sara Mantovani, Jacopo Vannucci, Massimiliano Bassi, Daniele Diso, Federico Venuta \\ Department of Thoracic Surgery, University of Rome Sapienza, Rome, Italy \\ Correspondence to: Marco Anile, MD PhD. Department of Thoracic Surgery, University of Rome Sapienza, Viale del Policlinico 15500161 Rome, \\ Italy. Email: marco.anile@uniroma1.it. \\ Comment on: Patella M, Bartolucci DA, Mongelli F, et al. Spiral wire localization of lung nodules: procedure effectiveness and oncological usefulness. \\ J Thorac Dis 2019;11:5237-46.
}

Submitted Feb 29, 2020. Accepted for publication Apr 09, 2020.

doi: $10.21037 /$ jtd.2020.04.56

View this article at: http://dx.doi.org/10.21037/jtd.2020.04.56

Because of increased indications for videothoracoscopic (VATS) lung resection with different modalities (triportal, biportal, uniportal, subxiphoyd approaches), the nodule localization has often become a challenge for surgeons. If in case of a superficial lesion, close to the pleura surface and solid the instrumental palpation instead of hand manipulation is usually easy, safe and helpful to completely remove it, the localization of a ground glass opacity (GGO) or a deep nodule may represent a huge problem to solve, in particular when a sublobar resection is planned. Although lobectomy is still the gold standard treatment for operable lung cancer, several experiences in the last ten years have given an important boost to perform limited resections as wedges and segmentectomies with curative intent in case of early stage lung cancers, GGOs, metastatic lesions or in patients with poor respiratory reserve. This extremely minimally invasive approach (VATS plus limited resection) poses two main difficulties: the correct localization of the nodule and its safe removal with wide free margins to avoid local recurrences.

Different ways have been attempted to overcome the first concern with contradictory results. Endofingers as tactile sensor and intraoperative ultrasound have been initially developed, but these methods were ineffective in case of GGOs due to air component similar to surrounding normal parenchyma and for lesions localized in depth $(1,2)$. The placement of markers under CT scan guidance as hookwires shaped in different forms is the most preferred method; several types of products have been developed presenting different anchorage's systems, including the spiral wire proposed by Patella et al. (3-5), and all of these show advantages and some criticisms. The results showed by
Patella et al. (3) with the use of a spiral wire are encouraging in terms of feasibility, safety and stability during the patient transport towards operating room. As reported by authors, the particular shape of this marker is probably the key of their remarkable results. However, the gold standard marker should be easy to insert, stable during the transport after the insertion and during the surgical procedure, safe with a low complications rate and the technique should be easily reproducible worldwide. Actually none system seems to have all characteristics simultaneously, as also reported in the paper from Swiss experience that underlies how it is very important to have an high expertise on the procedure's planning and a technology adequate to perform it.

Also other types of markers as microcoils and dyes placed with fluoroscopy or fiberbronchoscopy with navigation systems require a dedicated instrumentation not always available $(6,7)$; furthermore, many authors consider as a possible and desirable future scenario the use of hybrid operative theaters where to bring together in one place two moments: diagnostic and surgical (8). If this could reduce the operative time with a benefit for the patients, in other hand it should increase the healthy costs due to the technology required. Although an ideal system has been not still proposed, however the need to avoid larger incisions to detect small nodules and the impressive boost towards minimally invasive procedures enforce to develop new techniques and methods facilitating surgeons in the nodule localization.

The other relevant aspect is relative to the complete removal of the nodule with adequate free margins. Often also a correct localization with markers or other methods is not sufficient to assure an oncological complete resection, since the nodule's morphology as in case of a GGO with 
a larger spread could be a limitation. To overcome this problem, a novel technique of lung mapping named VirtualAssisted Lung Mapping (VAL-MAP) has been developed allowing with the use of fiberbronchoscopy information and virtual images derived from a CT and 3D reconstruction to have a geometric vision of the nodule in the lung due to multiple virtual markers (9). Of course, this method is expensive but it allows preoperatively planning in a more correct way the resection.

Finally, in this golden age of sublobar resections, there is another aspect that could add in the future some confounding factors in the diagnosis and treatment of GGOs: this is the spread through air spaces (STAS). This is a tumor's characteristic and well-defined histopathologic entity, it is included in the staging of lung cancer and it is not detectable with the standard techniques of imaging. Although it is not still clear which are the underlying mechanisms favoring STAS and how the neoplastic cells can survive without an evident contact with the alveolar walls, it is well known that the presence of STAS represents a factor associated with a poor prognosis (10). The definition of STAS is micropapillary clusters, solid nests, or single cells beyond the edge of the tumor into air spaces in the surrounding lung parenchyma (11); however, it is not specified how far is the surrounding parenchyma. Now, in our not yet published experience, we have found STAS up to $2 \mathrm{~cm}$ from the tumor edge; this could make unsafely a sublobar resection with a high risk of local recurrence. Although with conventional imaging techniques is not possible to detect STAS, new imaging algorithms based on radiomics could be useful to preoperatively discriminate its presence; this could be in the future a new tool in the planning of surgical strategy (12).

In conclusion, actually the need to have a way to localize small nodules in VATS is mandatory and several techniques are still available; the safety, the efficacy and the worldwide reproducibility should be the main purposes of these products. New studies must be performed to seek the holy grail of markers, but new technologies are already developing in the next future.

\section{Acknowledgments}

Funding: None.

\section{Footnote}

Provenance and Peer Review: This article was commissioned by the editorial office, Fournal of Thoracic Disease. The article did not undergo external peer review.

Conflicts of Interest: All authors have completed the ICMJE uniform disclosure form (available at http://dx.doi. org/10.21037/jtd.2020.04.56). FV serves as the unpaid editorial board member of Fournal of Thoracic Disease from Aug 2019 to Jul 2021. The other authors have no conflicts of interest to declare.

Ethical Statement: The authors are accountable for all aspects of the work in ensuring that questions related to the accuracy or integrity of any part of the work are appropriately investigated and resolved.

Open Access Statement: This is an Open Access article distributed in accordance with the Creative Commons Attribution-NonCommercial-NoDerivs 4.0 International License (CC BY-NC-ND 4.0), which permits the noncommercial replication and distribution of the article with the strict proviso that no changes or edits are made and the original work is properly cited (including links to both the formal publication through the relevant DOI and the license). See: https://creativecommons.org/licenses/by-nc-nd/4.0/.

\section{References}

1. Nomori H, Horio H. Endofinger for tactile localization of pulmonary nodules during thoracoscopic resection. Thorac Cardiovasc Surg 1996;44:50-3.

2. Khereba M, Ferraro P, Duranceau A, et al. Thoracoscopic localization of intraparenchymal pulmo- nary nodules using direct intracavitary thoracoscopic ultrasonography prevents conversion of VATS procedures to thoracotomy in selected patients. J Thorac Cardiovasc Surg 2012;144:1160-5.

3. Patella M, Bartolucci DA, Mongelli F, et al. Spiral wire localization of lung nodules: procedure effectiveness and oncological usefulness. J Thorac Dis 2019;11:5237-46.

4. Yoshida Y, Inoh S, Murakawa T, et al. Preoperative localization of small peripheral pulmonary nodules by percutaneous marking under computed tomography guidance. Interact CardioVasc Thorac Surg 2011;13:25-8.

5. Chen S, Zhou J, Zhang J, et al. Video-assisted thoracoscopic solitary pulmonary nodule resection after CT-guided hookwire localization: 43 cases report and literature review. Surg Endosc 2011;25:1723-9.

6. Okumura T, Kondo H, Suzuki K, et al. Fluoroscopy- 
assisted thoracoscopic surgery after computed tomography-guided bronchoscopic barium marking. Ann Thorac Surg 2001;71:439-42.

7. Endo M, Kotani Y, Satouchi M, et al. CT fluoroscopyguided bronchoscopic dye marking for resection of small peripheral pulmonary nodules. Chest 2004;125:1747-52.

8. Zhao ZR, Lau RWH, Yu PSY, et al. Devising the guidelines: the techniques of pulmonary nodule localization in uniportal video-assisted thoracic surgeryhybrid operating room in the future. J Thorac Dis 2019;11;S2073-8.

9. Sato M, Kobayashi M, Kojima F, et al. Effect of virtualassisted lung mapping (VAL-MAP) in acquisition of surgical margins in sublobar lung resection. J Thorac

Cite this article as: Anile M, Mantovani S, Vannucci J, Bassi M, Diso D, Venuta F. Seeking the holy grail of markers. J Thorac Dis 2020;12(10):5259-5261. doi: 10.21037/jtd.2020.04.56
Cardiovasc Surg 2018;156:1691-701.

10. Kadota K, Nitadori JI, Sima CS, et al. Tumor Spread Through Air Spaces is an important pattern of invasion and impacts the frequency and location of recurrences following limited resection for small stage I lung adenocarcinomas. J Thorac Oncol 2015;10:806-14.

11. Travis WD, Brambilla E, Nicholson AG, et al. The 2015 World Health Organization classification of lung tumors. Impact of genetic, clinical and radiologic advances since the 2004 classification. J Thorac Oncol 2015;10:1243-60.

12. Jiang C, Luo Y, Yuan J, et al. CT-based radiomics and machine learning to predict spread through air space in lung adenocarcinoma. Eur Radiol 2020;30:4050-7. 